\title{
МАКРОН И КРАМП-КАРРЕНБАУЭР: ФРАНКО-ГЕРМАНСКИЙ ДИАЛОГ О БУДУЩЕМ ЕВРОПЫ
}

\begin{abstract}
Аннотация. В статье проанализированы предложения президента Франции Э. Макрона, касающиеся реформ Европейского союза, а также ответ на них председателя Христианскодемократического союза А. Крамп-Карренбауэр. Авторы считают, что инициатива Э. Макрона имеет не только международное, но и внутриполитическое измерение, а эффективность франиузского подхода к перестройке Евросоюза зависит прежде всего от Германии. В связи с этим президенту Франции предстоит более интенсивно взаимодействовать с ФРГ в рамках согласованного мезебергского плана.
\end{abstract}

Ключевые слова: франко-германский тандем, Макрон, Крамп-Карренбауэр, европейская интеграция.

\section{Противоречивые идеи Э. Макрона}

4 марта 2019 г. на сайте Елисейского дворца было опубликовано обращение президента Франции к гражданам Европы ${ }^{1}$. На следующий день оно вышло в 28 ведущих газетах Евросоюза. Э. Макрон пошёл на беспрецедентный шаг, означающий, по сути, вмешательство во внутренние дела других стран - участниц ЕС и в начавшуюся избирательную кампанию в Европарламент, поскольку он, как официальное лицо, обращался не к правительствам, а напрямую к гражданам, воскрешая тем самым идею народного суверенитета, утвердившуюся в ходе Великой Французской революции.

Неслучайно в размышлениях Э. Макрона противопоставляются безответственность популистски настроенных элит, не пренебрегающих ложью, что, по его мнению, наиболее очевидно в выходе Великобритании из ЕС, и реакция «на [реальные] потребности народов в защите». Последнее, убеждён президент, должно характеризовать поведение ответственных элит. В таком противопоставлении имеется опасность разделения Евросоюза на «хороших» и «плохих» и допускается отказ от сотрудничества с теми, кто не собирается учитывать реальные потребности народа/ов или будет препятствовать волеизъявлению. Причём Э. Макрон не собирается услышать никаких иных вариантов, кроме вывода о том, что национальная изоляция ничего не может предложить, тем самым означая отказ от любой перспективы.

Без внимания экспертов, к сожалению, осталась принципиальная, на наш взгляд, мысль

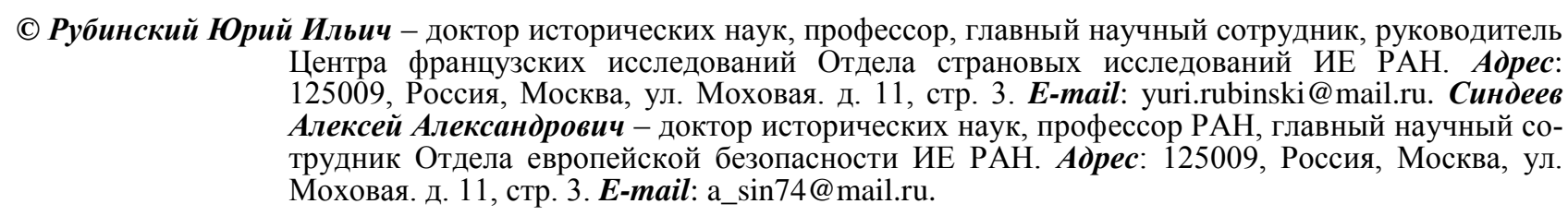
DOI:

1 Здесь и далее обращение Э. Макрона цит. по: Pour une Renaissance européenne. URL: www.elysee.fr/emmanuelmacron/2019/03/04/pour-une-renaissance-europeenne; Für einen Neubeginn in Europa. URL: www.elysee.fr/emmanu el-macron/2019/03/04/fur-einen-neubeginn-in-europa.de. 
французского президента, которую он завуалировал в вопрос: «Какая страна способна одна защищаться от агрессивных стратегий крупных держав?». Э. Макрон задумывается над постепенным видоизменением в общественном сознании содержательного наполнения «концепции великой нации», величие которой в настоящее время должно среди прочего состоять в способности не лидировать, а успешно (со)участвовать в реализации европейского проекта. В этой связи Э. Макрон признаёт статус-кво опасным, пишет именно о проекте и, страхуясь от потенциальных трудностей, о его постоянном изменении.

Хотя формально президент обращается ко всем гражданам ЕС, именно французам предлагается новая национальная идея - спасение европейской цивилизации, за что они уже частично и проголосовали на выборах 2017 г. «Наш континент, - констатирует Э. Макрон, стоит на перепутье... [и] мы вместе должны по-новому, в политическом и культурном смысле, найти оформление нашей цивилизации...», что немыслимо без конкретных институциональных предложений, которые по непонятным причинам многие комментаторы и эксперты отнесли к французскому стремлению всё отрегулировать. Объяснение упоминания новых органов следует искать в попытке французской стороны объединить солидерство и соучастие в европейском проекте.

Э. Макрон предлагает защищать демократию, создав соответствующее европейское агентство, которое получило бы право «направлять в каждое государство-член... экспертов», способных отразить «хакерски[е] нападени[я] и [не допустить] манипуляци[й]» выборами. Он высказался также за запрет «финансирования европейских политических партий иностранными государствами», за более активную борьбу с «комментариями в Интернете, содержащими ненависть и насилие», за принятие новых правил для шенгенской зоны со строгим пограничным контролем, с «общ[ей] политик[ой] по предоставлению убежища» и «совместн[ой] пограничн[ой] полицией и европейск[им] ведомств[ом] по убежищу», находящимися под надзором «Европейского совета по внутренней безопасности».

Французский президент настаивает на предельно чёткой фиксации целей Евросоюза в сфере обороны, что, по его мнению, потребует заключения нового договора, в котором содержались бы «обязательства, касающиеся обороны и безопасности», а именно: «повышение военных расходов, возможность применения формулы совместной обороны, [создание] Европейск[ого] совет[а] безопасности» с Великобританией.

Всё это существенно усиливает традиционное африканское направление внешней политики Франции, которому Э. Макрон в рамках подписания «Пакта во имя будущего» и включения в него принципа «общности судеб» со странами Африки, намеревается придать европейский характер.

Французский президент хочет защищать Европу и посредством реформирования конкурентной и торговой политики. Желательным для него стали бы наказание или запрет деятельности «предприятий... которые подрывают наши стратегические интересы и наши основные ценности... стандарты по охране окружающей среды, защите данных и уплате налогов в разумном объёме». Европейский протекционизм должен быть распространён на «стратегически[е] отрасл[и] и на общественные заказы». В этом контексте следует понимать известную инициативу президента в отношении глобальных интернет-корпораций и образования Европейского инвестиционного совета, который финансировал бы проекты, связанные с искусственным интеллектом.

Стремясь избавиться от имиджа технократа, Э. Макрон высказывается за единые «социальные гарантии» и «европейскую минимальную заработную плату». Тем самым он, по всей видимости, не прочь возглавить движение по защите прав лиц наёмного труда. 


\section{Смещение акцентов в тактике французского президента}

Призыв Э. Макрона к «возрождению Европы», адресованный гражданам всех стран членов ЕC, имеет не только международное, но и внутриполитическое измерение ${ }^{1}$. Протестное движение «жёлтых жилетов» во Франции, начавшееся в ноябре 2018 г. и продолжающееся четыре месяца подряд, стало реакцией на противоречивые итоги программы радикальной перестройки экономической модели страны, с которой президент пришёл в Елисейский дворец. Характерно, что за полтора года работы доверие к нему снизилось с 64 до $31 \%$.

Между тем эта программа изначально органически вписывалась в проект модернизации $\mathrm{EC}$, изложенный Э. Макроном в вышедшей во время президентских выборов 2017 г. автобиографической книге «Революция», а затем прозвучавший в ряде резонансных публичных выступлений в Афинах, Сорбонне, Аахене 2 . Поэтому очередные выборы в Европарламент 23-26 мая 2019 г. стали важной проверкой как общих перспектив реализации европейского проекта Э. Макрона, так и шансов на его успешное завершение в последующие три года первого президентского мандата, после чего он твёрдо намерен бороться за второй. Именно эта двойная задача определила содержание его послания, в котором можно увидеть некоторые новые акценты.

Хотя главными противниками Э. Макрона безусловно являются национал-популистсткие евроскептики - М. Ле Пен во Франции, В. Орбан в Венгрии или М. Сальвини в Италии, президент тщательно избегает называть их конкретно. При этом он учитывает настроения части протестного «народного» электората, которого серьёзно тревожат проблемы массовой миграции из мусульманских стран Африки и Ближнего Востока, конкуренция динамичных центров силы в Азии и угрозы безопасности (в том числе в киберпространстве) на фоне ослабления трансатлантических связей с США при президенте Д. Трампе.

Поэтому Э. Макрон тщательно корректирует свой прежний либерально-глобалистский дискурс, делая упор на необходимость совместного контроля Евросоюза над иммиграционными потоками, на охрану общих внешних границ, на обеспечение автономной от НАТО оборонной идентичности. В том же ключе следует понимать его призывы противодействовать финансированию политических партий из иностранных источников и вмешательству извне в политическую жизнь государств Евросоюза, их выборы, дать отпор кампании «ложных новостей» (fake news) через контролируемые иностранными государствами СМИ.

Если раньше европеизм рассматривался как естественное дополнение атлантизма и глобализма (под флагом защиты свободы торговли), то теперь акценты переносятся на борьбу, в т.ч. и жёсткими протекционистскими мерами, против недобросовестной конкуренции с участием государств, технологического шпионажа, угроз независимости стратегически важным позициям европейской экономики, вызываемых среди прочего инвестициями и кредитами. Призывы обеспечить «коллективный суверенитет» стран ЕС перед лицом внешних вызовов имеют вполне определённых адресатов - как политических (РФ), так и экономических (КНР).

Наряду с проблемами безопасности и суверенитета Э. Макрон стремится перехватить у своих противников и некоторые типично популистские лозунги. Речь идёт о требовании «жёлтых жилетов» дополнить элитарную представительную демократию прямыми формами, например, «референдумом гражданской инициативы» (RIC - Le référendum d'initiative citoyenne), на котором рядовые граждане обсуждали бы касающиеся их местные и общегосударственные вопросы.

\footnotetext{
${ }^{1}$ См. также: Рубинский Ю.И. Франция: прощание с биполярностью? Научно-аналитический Вестник Института Европы РАН, №1, 2018 г. С. 99-105.

${ }^{2}$ Macron E. Révolution: C'est notre combat pour la France. Paris: XO Editions, 2016.
} 
Внутриполитическим ответом президента стала организация «больших дебатов» об условиях «национального контракта» - на уровне коммун, департаментов и регионов с участием мэров, министров, премьер-министра, самого́ главы государства, а также представителей структур гражданского общества и социальных партнёров. Собранные предложения («тетради жалоб») должны быть переданы на рассмотрение обеих палат парламента. В ходе «больших дебатов» только по электронной почте поступили 469200 инициатив. Однако соцопросы показали, что лишь $37 \%$ респондентов надеются на их последующую реализацию правительственными кругами, $63 \%$ сомневаются в этом ${ }^{1}$.

С учётом весьма ограниченной эффективности «больших дебатов» в преодолении национального социального кризиса, проявившегося в движении «жёлтых жилетов» и их радикализации, принявшей форму беспорядков и погромов экстремистов на центральной улице Парижа - Елисейских полях, Э. Макрон попытался придать своей инициативе европейский масштаб. Именно такой смысл имеет сформулированная в обращении к гражданам стран членов ЕС идея провести «конференцию для Европы», на которой мог бы быть согласован, а по существу легитимирован президентский проект перестройки структуры Евросоюза.

Принимая во внимание то обстоятельство, что в ряде государств Центральной и Восточной Европы (в Венгрии, Чехии, Словакии, Польше, Австрии), а отчасти и Южной Европы (в Италии) национал-популистские скептики пришли к власти, Э. Макрон предпочёл избежать обсуждения привычных для него прежде тем - ведущей роли франко-германского тандема и необходимости консолидации зоны евро, к которой принадлежат только 19 из 28 государств ЕС (до брекзита $)^{2}$.

Следует отметить, что тактическая эволюция либерально-глобалистского дискурса Э. Макрона вызвала зеркальную, обратную реакцию его непримиримых противников - национал-популистских «суверенистов». Так, лидер французской партии «Национальное объединение» Марин Ле Пен по сути сняла требование выхода из зоны евро, тогда как венгерский лидер Виктор Орбан стал подчёркивать решимость сохранить членство в Европейском союзе при условии пересмотра основополагающих договоров в духе расширения прав национальных парламентов и правительств ${ }^{3}$.

Поскольку Франция не сможет без успехов в европейском проекте обеспечивать развитие своей национальной модернизационной модели, эффективность новых акцентов во французском подходе к перестройке Евросоюза зависит прежде всего от привилегированного партнёра Парижа - Германии. Последняя переживает сложный процесс транзита власти - отказа А. Меркель от руководства ХДС и её ухода с поста федерального канцлера ${ }^{4}$.

\section{Сдержанный ответ АКК}

Аннегрет Крамп-Карренбауэр (АКК), председателю ХДС, не имеющей правительственных должностей, было легче ответить французскому президенту. По словам генерального секретаря ХДС П. Цимиака, содержание статьи АКК, появившейся 10 марта 2019 г. в «Вельт ам Зоннтаг», было заранее согласовано с канцлером А. Меркель ${ }^{5}$. Впрочем, иного формата от-

\footnotetext{
${ }^{1}$ Из этих предложений 157 тыс. касаются налоговой системы и бюджетных расходов, 126 тыс. - экологии, 93 тыс. - демократии и гражданства, 92 тыс. - структуры государства (BFM TV. News, 6 mars 2019).

${ }^{2}$ См. подробнее о европейском проекте Макрона: Фёдоров С.М. «План Макрона» для Европы: новый старт европейского проекта в XXI веке? Современная Европа. №6, 2018 г. С. 30-39.

${ }^{3}$ Не исключено, что В. Орбан учитывал угрозу приостановки членства его партии в Европейской народной партии перед выборами в Европарламент.

${ }^{4}$ Рубинский Ю.И. Франко-германский тандем: прошлое и будущее. Современная Европа: 60 лет после Римских договоров. Часть І. ДИЕ РАН №340. М., ИЕ РАН, 2017. С. 65-76.

5 Здесь и далее статья АКК цит. по: Europa jetzt richtig machen. URL: www.welt.de/politik/deutschland/article19003
} Научно-аналитический вестник ИЕ РАН, 2019, №2 
вета Э. Макрону ожидать и не приходилось, так как сотрудники французского МИД при необходимости могли бы проинформировать президента о европейских положениях действующего в ФРГ коалиционного договора, о границах, которые канцлер в сложной ситуации работы «большой коалиции» не собиралась нарушать. Руководство ХДС сознательно перевело диалог с французскими коллегами на партийный уровень, предоставив возможность официальным лицам других партий Германии также высказаться в развёрнутых газетных статьях по поводу обращения Э. Макрона, что, кстати, на данный момент пока никто из них не сделал.

АКК отказалась от упоминания европейской цивилизации, предпочтя более нейтральное понятие «европейский образ жизни», призвала не сомневаться в проевропейском настрое граждан ЕС и выступила за конкуренцию различных концепций на этапе избирательной кампании в Европарламент, что, по сути, означало следующее: европейский проект - это общий знаменатель полученного после выборов расклада сил; тогда его и имеет смысл обсуждать.

Однако магистральное направление А. Крамп-Карренбауэр определила довольно чётко. Будущее Европы, по её мнению, заключается в балансе между национальным и наднациональным, так как «[н]овое основание Европы невозможно без национальных государств: они создают демократическую легитимность и идентификацию». Причём гарантия «демократическ[ой] легитимност[и] для... новой Европы» обеспечивается привлечением всех участников интеграции, что предотвращает разделение стран на «хорошие» и «плохие». Не вызывают сомнений и приоритеты сотрудничества в рамках интеграции: для АКК они обусловливаются «стратегическ[ой] сил[ой] нашей промышленности, технологи[ями] и инноваци[ями], чувство[м] безопасности наших граждан и общи[ми] внешнеполитически[ми] компетенци[ями] и компетенци[ями] в сфере безопасности», помогающими добиваться реализации европейских интересов.

Поэтому в отличие от Э. Макрона АКК выносит на обсуждение не систему, а отдельные, подчас слабо связанные друг с другом, предложения, сохраняя пространство для манёвра после майских выборов. В этой связи разбирать подробно все её предложения не имеет особого смысла, как и придавать излишнее значение часто анализируемой цитате, свидетельствующей о якобы жёстком отказе Э. Макрону: «... мы должны, - пишет АКК, - сделать ставку на субсидиарность, собственную ответственность и связанную с ней материальную ответственность. Европейский централизм, европейский этатизм, обобществление долгов, европеизация социальных систем и минимальная заработная плата были бы неправильным путём». Во-первых, французский президент в этот раз не писал об обобществлении долгов. Вовто-рых, АКК не заявила о том, что европейская минимальная оплата труда является навсегда «неправильным путём». Наверняка, как об этом неоднократно и говорилось, это неправильный путь до тех пор, пока не произошла «конвергенци[я] в смысле равных условий жизни внутри государств-членов и между государствами-членами».

Причины сдержанного ответа АКК заключаются в том, что она лишь нарабатывает авторитет и не забыла о минимальном перевесе голосов на прошлогоднем декабрьском съезде ХДС, позволившем ей возглавить партию, которая переживает очередную стадию примирения различных течений. АКК едва ли забыла также о том, что впервые ХДС и ХСС совместно выставили на выборах в Европарламент кандидата, имеющего неплохие шансы возглавить Еврокомиссию. Она не может рисковать единством христианских партий и давать повод для излишних дискуссий. Поэтому ответ Э. Макрону - это не отказ от сотрудничества, а сигнал,

7115/AKK-antwortet-Macron-Europa-richtig-machen.html; Faisons l'Europe comme il faut. URL: www.lefigaro.fr/ vox/monde/2019/03/10/31002-20190310ARTFIG00083-annegret-kramp-karrenbauer-faisons-l-europe-comme-il-faut. php.

Научно-аналитический вестник ИЕ РАН, 2019, №2 
что серьёзное обсуждение следует начинать позднее.

У Э. Макрона, таким образом, выбор невелик: либо он будет работать с А. Меркель в рамках мезебергского плана, либо он будет продолжать по-новому расставлять акценты и выдвигать новые несогласованные с немецкой стороной инициативы, но тогда ему придётся обсуждать их с АКК. Первый путь даст результаты и позволит отчитаться перед гражданами Франции, второй - потребует временных затрат и принесёт в лучшем случае минимальный успех. Попытка соединить мезебергский план и диалог о будущем Европы в этой ситуации бессмысленна, ведь немецкая сторона пока настаивает на разведении форматов и их содержательного наполнения.

\section{Список литературы}

Рубинский Ю.И. Франко-германский тандем: прошлое и будущее. Современная Европа: 60 лет после Римских договоров. Часть І. ДИЕ РАН №340. М., ИЕ РАН, 2017. С. 65-76.

Рубинский Ю.И. Франция: прощание с биполярностью? Научно-аналитический Вестник Института Европы РАН, №1, 2018. С. 99-105.

Фёдоров С.М. «План Макрона» для Европы: новый старт европейского проекта в XXI веке? Современная Европа, №6, 2018. С. 30-39.

Macron E. Révolution: C'est notre combat pour la France. Paris: XO Editions, 2016.

\section{References}

Rubinskii Yu.I. Franko-germanskii tandem: proshloe i budushchee. Sovremennaya Evropa: 60 let posle Rimskikh dogovorov. Chast’ I. DIE RAN № 340. Evropy». M., IE RAN, 2017. S. 65-76.

Rubinskii Yu.I. Frantsiya: proshchanie s bipolyarnost'yu? Nauchno-analiticheskii Vestnik Instituta Evropy RAN, №1, 2018. S. 99-105.

Fyodorov S.M. «Plan Makrona» dlya Evropy: novyi start evropeiskogo proekta v XXI veke? Sovremennaya Evropa, №6, 2018. S. 30-39.

Macron E. Révolution: C'est notre combat pour la France. Paris: XO Editions, 2016.

\section{Macron and Kramp-Karrenbauer: Franco-German dialogue on the future of Europe}

The Authors. Yuriy Rubinskiy, Doctor of Sciences (History), Professor, Chief Research Associate, Head of the Centre for Studies of France, Department of Country Studies, Institute of Europe, Russian Academy of Sciences. E-mail: yuri.rubinski@mail.ru; Alexey Sindeev, Doctor of Sciences (History), Professor of RAS, Chief Research Associate, Department of European Security, Institute of Europe, Russian Academy of Sciences. E-mail: a_sin74@mail.ru. Address: 11-3, Mokhovaya str., Moscow, Russia, 125009.

Abstract. The paper evaluates the proposals made by French President E. Macron for reforming the EU. These proposals are compared with the response of A. Kramp-Karrenbauer, chairman of the CDU. The authors believe that the Macron initiative has not only international, but also domestic political reasons. The success of Macron's proposals depends on the support of the German side. Therefore, Macron is probably forced to continue the cooperation with the Federal Republic within the framework of the Meseberg plan.

Key words: Franco-German tandem, Macron, Kramp-Karrenbauer, European integration.

DOI: http://dx.doi.org/10.15211/vestnikieran220192025 